\title{
Multi-Minicore Disease: A Report of 5 Patients from Kuwait
}

\author{
E.S. Al-Jumah ${ }^{a}$ Y.K. Habeeb ${ }^{a}$ M.A. Al-Bloushi ${ }^{a} \quad$ A. Moosa a,b \\ ${ }^{a}$ Department of Paediatric Neurology, Mubarak Al-Kabeer Hospital and ${ }^{b}$ Faculty of Medicine, Kuwait University, \\ Kuwait
}

\section{Key Words}

Multi-minicore disease $\cdot$ Clinical variability .

Muscle histochemistry

\begin{abstract}
Objective: To describe the characteristic clinical features and the diagnostic findings in muscle histochemistry of multi-minicore disease in 5 children from two unrelated families in Kuwait. Clinical Presentation: The 5 children who presented with muscle weakness, 2 siblings from family 1 and the remaining 3 from the other (family 2 ), represent the classical type of multi-minicore disease; however, the two families differ in the course of the disease. Family 1 had the non-progressive form while family 2 had progressive weakness with respiratory complications and scoliosis. The diagnosis was confirmed in the index patients by muscle histochemistry, which demonstrated the typical minicores, which are devoid of oxidative enzyme activity. Conclusion: Both families represent the classical form, however, clinical variability in the course of the illness was demonstrated in these two families.
\end{abstract}

Copyright $(2005$ S. Karger AG, Basel

\section{Introduction}

Multi-minicore myopathy is one of the congenital myopathies, characterized by the presence of multiple minicores usually found at the periphery of muscle fibres. Minicores represent small areas of loss of mitochondrial activity and sarcomeric disorganization. The absence of clear dominant transmission in any well-established case and the presence of several consanguineous families strongly suggest that multi-minicore myopathy is an autosomal recessive entity [1]. Marked hypotonia with weakness is the consistent feature, which affects axial and proximal muscles, especially the shoulder girdle. Rarely does distal weakness with hand amyotrophy occur $[2,3]$. Mild facial weakness is frequently observed and complete external ophthalmoplegia may be present in some severely affected patients [3].

Prenatal onset with decreased fetal movement and polyhydramnios, congenital deformity including arthrogryposis, talipes equinovarus and congenital hip dislocation, feeding difficulty requiring nasogastric tube feeding, respiratory failure and congenital ptosis are associated features $[2,3]$.

The course of the illness is usually static or slowly progressive [3, 4], but may be associated with serious complications such as cardiomyopathy, respiratory failure, scoliosis and malignant hyperthermia [5, 6]. Diagnosis of this illness is made by muscle biopsy.

Dr. Eman S. Al-Jumah

Department of Paediatric Neurology

PO Box 5302

13054 Safat (Kuwait)

Tel./Fax +965 53957 07, E-Mail emansmay@yahoo.com 


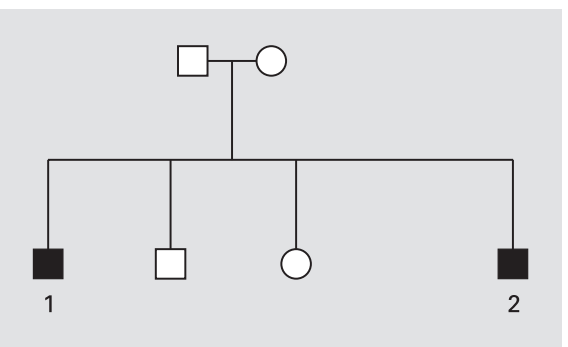

Fig. 1. Pedigree of family 1.

Fig. 2. Patient 1 from family 1 showing drooping and wasting around shoulder (a), winging of scapula (b) and myopathic face (c).
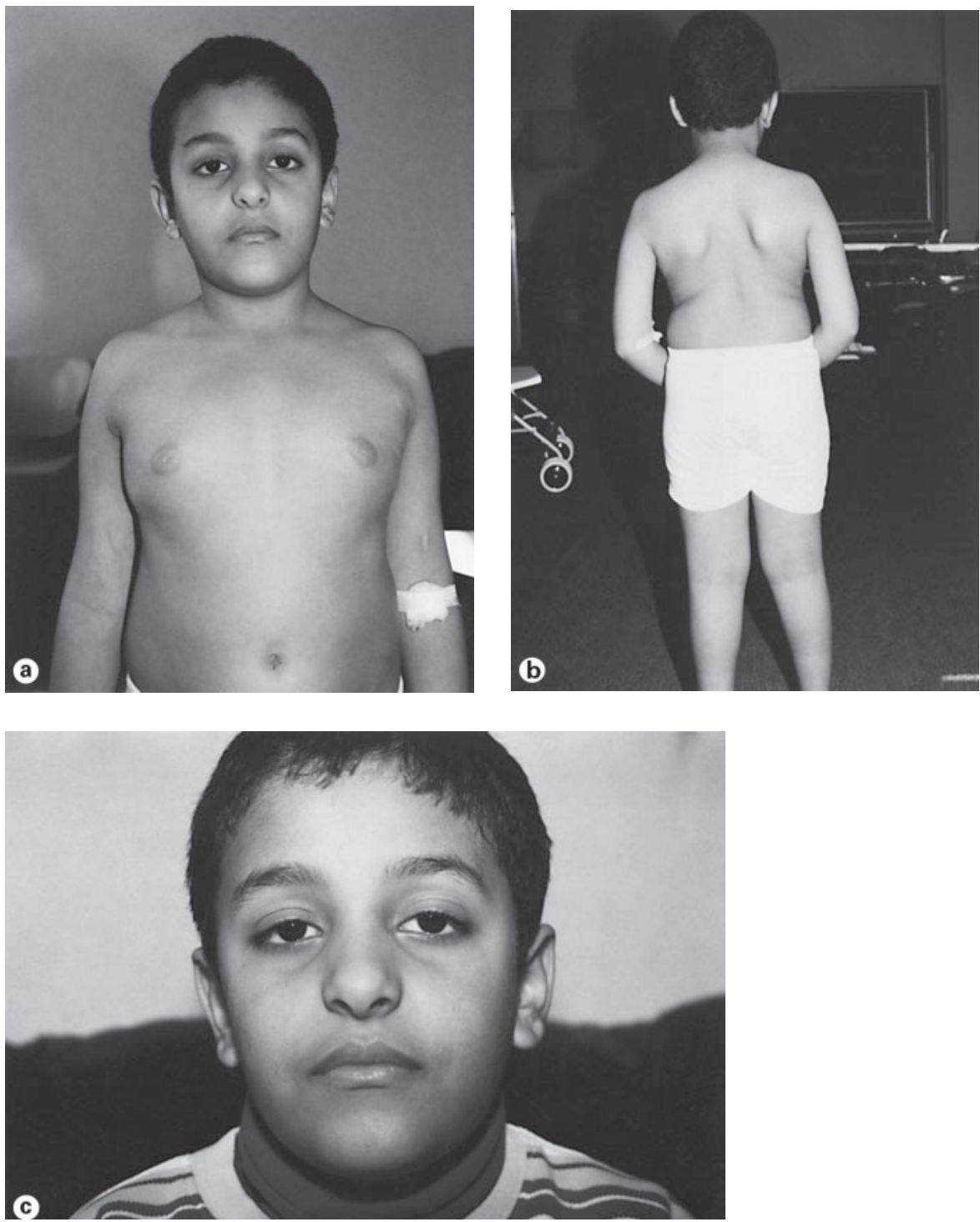

We describe 5 cases with the diagnosis of multi-minicore disease from two families. Clinical variability was evident in these cases. We believe that this is the first report of multi-minicore disease in the Middle East.

\section{Case Reports}

\section{Family 1 (fig. 1)}

\section{Subject 1}

The patient, a 9-year-old boy (fig. 2), was born by caesarean section because of fetal distress; there was no neonatal problem. The main concern was motor developmental delay. He rolled over at
14 months, sat by 18 months, bottom shuffled and cruised at 19 months and walked by 36 months. He climbed stairs at 54 months. He was not able to run normally. Parents were non-consanguineous and were both healthy. Examination showed no dysmorphic features, no ophthalmoplegia, tremor or fasciculations. He had generalized hypotonia with weakness that was more at the proximal muscles than distal. The shoulder girdle was more affected than the hips, giving it a drooping appearance. He had absent deep tendon reflexes, his gait was waddling and Gower's sign was positive. He was last seen at the age of 8 years, still ambulating with a myopathic face, lumbar lordosis and winging of the scapula. No obvious progression of the disease could be demonstrated.

Investigation showed normal creatine kinase, and electromyography $(E M G)$ and nerve conduction velocities. Muscle biopsy was performed at the age of 36 months. Routine histology showed variation in fibre size, increase in fibrosis and a large number of hyper- 

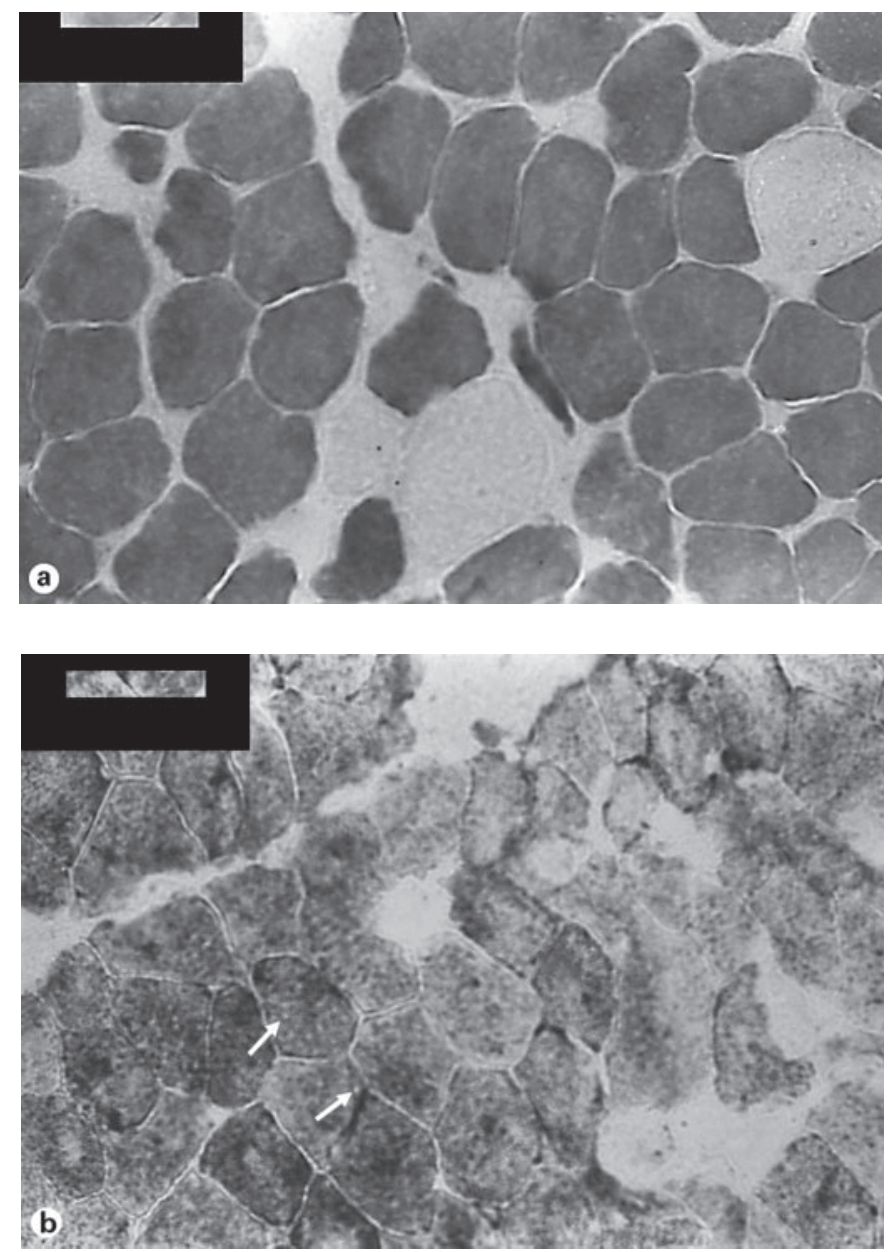

Fig. 3. Muscle of patient 1 showing type 1 fibre (dark fibres) predominance (ATPase $\mathrm{pH} 4.3, \mathbf{a}, \times 40$ ) and minicores (arrows, b, $\mathrm{NADH}, \times 40)$.

trophied whorled fibres. Enzyme histochemistry showed type I fibre predominance (fig. 3a). Most fibres showed disorganization of the architecture on NADH stain, with many showing central and eccentric cores (fig. 3b) and aggregation of dense staining granules. The whorled fibres were of both type I and II. Staining for both dystrophin and sarcoglycans was normal.

\section{Subject 2}

The younger brother (fig. 4) of subject 1 was brought because of parental concern. He was full-term and also delivered by caesarean section, but he had decreased fetal movement. He was seen at the age of 10 and 15 months. He too had delayed motor development. He sat at 9 months with help, and could not walk or crawl at 15 months. He had poor head control because of axial muscle weakness, generalized hypotonia with weakness that affected his arm more than legs and absent deep tendon reflexes in upper limbs but not in the lower limbs. Neither facial weakness nor ophthalmoplegia was seen. Drooping of the shoulders was obvious and wasting of both the supraspinatus and the deltoid was present. Muscle bi-
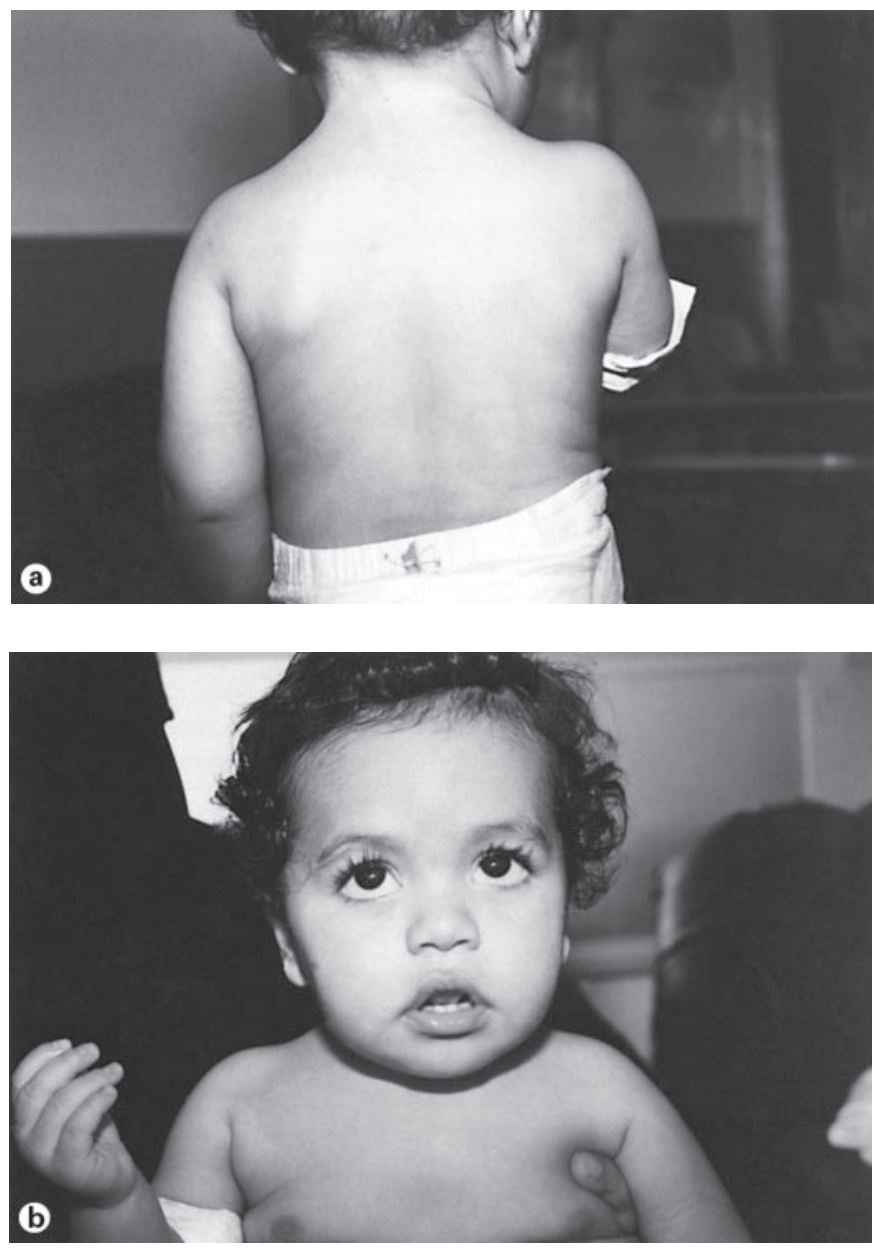

Fig. 4. Patient 2 from family 1 , younger sibling of patient shown in figure1. Note wasting around shoulders (a) and myopathic face (b).

opsy was not done because of the previously diagnosed brother. The two siblings are well but the younger (subject 2, fig. 4) was affected more by the disease.

\section{Family 2 (fig. 5)}

\section{Subject 3}

The patient, a 12-year-old boy, was first seen at the age of 7 years. He was born to healthy consanguineous parents. His birth history was unremarkable. The main concern was that he was having difficulty in getting up and down the stairs and could never run normally. Examination showed a myopathic face, ptosis, but no ophthalmoplegia, hypotonia with weakness in both upper and lower limbs and preserved deep tendon reflexes. Obvious wasting of both supra- and infraspinatus and early scoliosis were present. At the age of 11 years, he had a chronic cough that lasted for 1 year; he had difficulty chewing but not swallowing. He needed support to sit from a lying position or to stand from sitting. He could not walk 


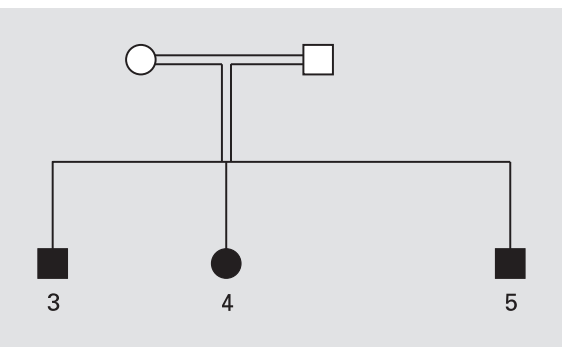

Fig. 5. Pedigree of family 2.

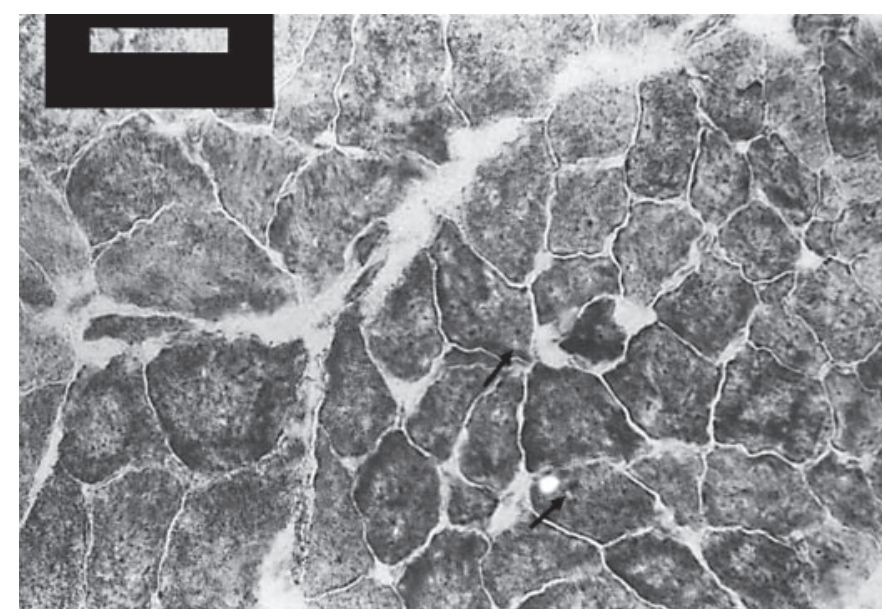

Fig. 6. Muscle of patient 3 of family 2 showing multiple minicores. NADH. $\times 40$.

for more than $50 \mathrm{~m}$ and was starting to use a wheelchair. He had more proximal than distal weakness and his lower limbs were more affected than the upper limbs. He had hyporeflexia and wasting of the interossei muscles. Investigation showed normal creatine kinase and myopathic changes on EMG. Pulmonary function tests at the age of 7 years showed a pattern that was compatible with restrictive airway disease. The muscle biopsy showed variation in fibre size with focal areas of degeneration and phagocytosis and increased endomysial and perimysial connective tissues. Histochemistry showed striking type I fibre predominance with almost all the fibres being type I. Many fibres showed multiple minicores of the myofibres (fig. 6). Dystrophin and sarcoglycan stainings were normal.

\section{Subject 4}

This is the sister of subject 3 . She was 11 years old and was brought with her brother at their initial visit when she was 5 years old. There was no concern about her initial development but later was observed to have frequent falls, difficulty in climbing stairs and in getting up from the sitting position. Examination revealed a myopathic face, no ophthalmoplegia, generalized hypotonia with weakness and hyporeflexia. The weakness was more proximal than distal with marked wasting of both supra- and infraspinatus muscles. From the age of 7 years she began to have recurrent respira- tory infections and choking due to oropharyngeal incoordination. At the age of 10 years, scoliosis and ptosis were detected.

Investigation showed normal creatine kinase. EMG was myopathic. Muscle biopsy showed considerable variation in fibre size, many large whorled fibres and an excessive number of internal nuclei. Histochemistry showed type I fibre predominance and many fibres showed multiple eccentric cores that were devoid of oxidative enzyme activity.

\section{Subject 5}

The patient was 7.5 years old, seen initially at the age of 3.5 years because he was having difficulty in getting up from the floor. $\mathrm{He}$ also had speech delay.

Examination showed mild facial weakness with ptosis, and more proximal muscle weakness than distal. By the age of 6 years he was found to have wasting of the muscles of his shoulder girdle and the hands, winging of the scapula and lumbar lordosis. Respiratory symptoms started by the age of 6.5 years. Investigation showed myopathic changes on EMG. Muscle biopsy was not done because of the diagnosis of the previously affected siblings.

\section{Discussion}

We report 5 individuals with multicore myopathy from two different families. In both families, autosomal recessive inheritance was the most likely mode of inheritance as suggested by more than 1 affected child and asymptomatic parents. In addition, in the second family there was parental consanguinity.

Different clinical phenotypes have been described in the literature $[1,2]$. Classical multi-minicore disease is the most common type with a highly consistent phenotype marked by axial predominance of muscle weakness and a high occurrence of severe respiratory insufficiency and scoliosis. The main clinical findings in this type are summarized in table 1 , which compares the clinical features of our patients with those reported in the literature.

Both families represent the classical phenotype but differ in the course of illness, which is static in family 1 , typical for most cases, while in family 2 it is slowly progressive with the occurrence of complications that include respiratory problems and scoliosis. A severe form with pharyngolaryngeal involvement and lack of head control was considered to form a particular subgroup. These probably represent the most severe cases in the classical form [1].

The other three clinical phenotypes are rare and include: (a) antenatal onset with arthrogryposis, in which dysmorphic features and congenital generalized arthrogryposis due to severe antenatal akinesia occur; (b) slowly progressive weakness with marked hand amyotrophy, 
Table 1. Main clinical findings of classical form of multi-minicore disease

\begin{tabular}{|c|c|c|c|c|c|c|}
\hline \multirow[t]{3}{*}{ Signs } & & \multicolumn{5}{|c|}{ Our patients } \\
\hline & & \multicolumn{2}{|c|}{ family 1} & \multicolumn{3}{|c|}{ family 2} \\
\hline & & 1 & 2 & 3 & 4 & 5 \\
\hline \multicolumn{7}{|l|}{ First signs } \\
\hline Neonatal manifestation & $46.7 \%$ & - & - & - & - & - \\
\hline Delayed motor milestones & $73.3 \%$ & + & + & - & - & - \\
\hline Poor motor performance in later childhood & $13.3 \%$ & - & - & + & + & + \\
\hline Facial muscle weakness & $56.7 \%$ & + & - & + & + & + \\
\hline Limb joint contractures & $33.3 \%$ & - & - & - & - & - \\
\hline Spinal abnormalities & $86.7 \%$ & & & & & \\
\hline Lordosis & $10 \%$ & + & - & - & - & + \\
\hline Scoliosis & $73.3 \%$ & - & - & + & + & - \\
\hline Others (spinal rigidity, kyphosis) & $20 \%$ & - & - & - & - & - \\
\hline Respiratory involvement & $60 \%$ & - & - & + & + & + \\
\hline Cardiac abnormalities & $23.3 \%$ & - & - & - & - & - \\
\hline
\end{tabular}

Percentages are from Ferrio et al. [2]. - = Not present; + = present. in which there is marked distal weakness of upper limbs with amyotrophy of intrinsic hand muscles and almost normal distal muscles of the lower limbs; (c) ophthalmoplegic form in which patients show external ophthalmoplegia of variable severity in addition to generalized muscle involvement similar to that described for the classical type. In this ophthalmic form, facial weakness is severe.

Diagnosis of multi-minicore disease is made by muscle biopsy. The characteristic features include predominance of type I fibres and the presence of well-defined cores with loss of intermyofibrillary mitochondrial activity [4] as observed in the present cases. These cores are usually located in the peripheral portion of the myofibres and the core size measures $10-20 \mu \mathrm{m}$ in diameter. Electron microscopic examination shows circumscribed areas of disintegrated $\mathrm{Z}$ band material and disorganized sarcomeric units near the sarcolemma. A decrease in the number of mitochondria and glycogen particles is also noted.
Molecular genetic studies have been in progress. Preliminary results of genetic studies in the literature seem to confirm that genetic heterogeneity underlies the phenotypic variability of multi-minicore disease [1]. There is no specific treatment, but careful surveillance for respiratory complications (especially nocturnal hypoventilation), scoliosis and rarely cardiomyopathy is important. Anaesthetists need to be aware of the diagnosis given the potential risk of malignant hyperthermia [5].

\section{Conclusion}

The 5 patients represent the classical form of multiminicore disease; the two families differed in the course of the illness, with family 1 typical of the classical nonprogressive phenotype while family 2 has progressive disease with respiratory symptoms and scoliosis.

\section{References}

1 Ferreiro A, Fardeau M: Workshop report: 80th ENMC International Workshop on MultiMinicore Disease A. Neuromuscul Disord 2002; 12:60-68.

$\checkmark 2$ Ferrio A, Estournet B, Chateau D, Roero NB, Laroche C, Odent S, Toutain A, Cabello A Fontan D, dos Santos HG, Haenggeli CA, Bertini E, Urtizberea JA, Guicheney P, Fardeau M: Multi-minicore disease-searching for boundaries: phenotype analysis of 38 cases. Ann Neurol 2000;48:745-757.
-3 Jungbluth H, Sewry C, Brown SC, Manzur AY, Mercuri E, Bushby K, Rowe P, Johnson MA, Hughes I, Kelsey A, Dubowitz V, Muntoni F: Minicore myopathy in children: a clinical and histopathological study of 19 cases. Neuromuscul Disord 2000;10:264-273.

4 Myong NH, Kang YK, Chi JG, Suk SI: Multicore myopathy - a case report. J Korean Med Sci 1993;8:312-317.
5 Rowe PW, Eagle M, Pollitt C, Bullock RE, Bushby KM: Multicore myopathy: respiratory failure and paraspinal muscle contractures are important complications. Dev Med Child Neurol 2000;42:340-343.

-6 Koch BM, Bertorini TE, Eng GD, Boehm R: Severe multicore disease associated with reaction to anesthesia. Arch Neurol 1985;42:12041206. 